\title{
Aplicação de glyphosate na dessecação do sorgo biomassa ${ }^{1}$
}

\section{Glyphosate application in burndown of biomass sorghum}

\author{
André May²; Ronaldo da Silva Viana ${ }^{3}$; Michelli de Souza dos Santos ${ }^{4}$; Evandro Henrique \\ Figueiredo Moura da Silva ${ }^{5}$
}

\begin{abstract}
Resumo - O sorgo biomassa é uma alternativa para a geração de energia renovável pela queima em caldeiras, destacando-se por sua alta produtividade e possibilidade de mecanização de todos os seus processos agrícolas. Uma alternativa comum para a redução da umidade de culturas é a aplicação de herbicidas dessecantes, contudo, não há pesquisas que elucidem a perda de umidade da massa colhida de sorgo com a aplicação de dessecantes na parte aérea, antes da colheita. Assim, o objetivo deste trabalho foi avaliar aplicação de glyphosate na dessecação do sorgo. $\mathrm{O}$ delineamento experimental utilizado foi em blocos inteiramente casualizados, no esquema fatorial $2 \times 5 \times 4$, constituídos por: duas cultivares de sorgo (BRS 716 e CR 1342); cinco doses de glyphosate $\left(0,720,1.440,2.160\right.$ e $2.880 \mathrm{~g}$ ingrediente ativo ha $\left.{ }^{-1}\right)$ e quatro épocas de coleta das plantas $(7,14$, 21 e 28 dias após a aplicação), com 4 repetições. Durante as diferentes épocas de coleta das plantas foram realizadas as avaliações da biomassa fresca e seca dos colmos e folhas e porcentagem de biomassa seca dos colmos e das folhas. A aplicação do glyphosate não foi eficaz no processo de dessecação das plantas de sorgo biomassa BRS 716 e CR1342.
\end{abstract}

Palavras-chaves: bioenergia; colheita; Sorghum bicolor

Abstract - The sorghum biomass is an alternative to a renewable energy generation by burning it in boilers, it stands out for its high productivity that occurs fully mechanized way. A common alternative to reduce the crop moisture is the application of herbicides. However, there is no researches showing the moisture reduction with burndown applications. Thus, this work aimed to evaluate the glyphosate application in drying of sorghum biomass. The experimental design was completely randomized in a factorial $2 \times 5 \times 4$ consisting of: two cultivars of sorghum biomass (BRS 716 and CR 1342); five glyphosate doses $(0,720,1,440,2,160$ and 2,880 $\mathrm{g}$ of the active ingredient $\left.\mathrm{ha}^{-1}\right)$ and four samplings of plants (7, 14, 21 and 28 days after application), with four repetitions. During the different samplings of plants were carried out evaluations of fresh and dry stem and dry matter percentage of culms. The application of glyphosate doses were not effective in the burndown process of biomass sorghum cultivars BRS 716 and CR1342.

Keywords: bioenergy; harvest; Sorghum bicolor

\footnotetext{
${ }^{1}$ Recebido para publicação em 18/08/2016 e aceito em 08/10/2016.

${ }^{2}$ Embrapa Milho e Sorgo, SP 340, km 127,5, Bairro Tanquinho Velho, CEP: 13820-000, Jaguariúna, São Paulo, Brasil. E-mail: <andre.may@embrapa.br>Autor para correspondência.

${ }^{3}$ Professor Assistente Doutor, Faculdades de Ciências Agrárias e Tecnológicas, UNESP, Dracena, São Paulo, Brasil. E-mail: <ronaldo@dracena.unesp.br>.

4 Pós-doutoranda na Embrapa Meio Ambiente, Jaguariúna, São Paulo, Brasil. E-mail: $<$ michellisantos30@hotmail.com>.

5 Mestrando na Universidade de São Paulo (ESALQ/USP), Piracicaba, São Paulo, Brasil. E-mail: <ehfmsilva@gmail.com>.
} 


\section{Introdução}

O sorgo (Sorghum bicolor (L.) Moench) é uma espécie vegetal da família Poaceae originária da África. O sorgo é o quinto cereal mais importante do mundo em termos de produção e área plantada (Steduto et al., 2012). No Brasil, segundo May et al. (2011), consideram-se cinco tipos de sorgo importantes para o mercado, sendo eles: granífero, forrageiro, pastejo, sacarino e lignocelulósico. Essa cultura tem apresentado crescente importância devido ao seu potencial na geração de bioenergia.

Há projeções de que a demanda por energia no mundo deverá crescer em $57 \%$ entre 2002 e 2025 e grande é o apelo da sociedade pela redução do uso de fontes de energia não renováveis (Lave et al, 2011). Nessa direção, o sorgo biomassa é uma alternativa para a geração de energia térmica renovável, pela queima em caldeiras. Destaca-se por sua alta produtividade - $150 \mathrm{t} \mathrm{ha}^{-1}$ de massa fresca em cinco meses e pela possibilidade de mecanização de todos os seus processos agrícolas (May et al, 2013). O poder calorífico do sorgo está ligado à umidade da biomassa colhida com consequente variação no potencial de geração e cogeração de energia, conforme a porcentagem de biomassa seca dos colmos das plantas. Assim, é importante desenvolver estratégias para a redução da umidade das plantas, visando elevar sua capacidade de produção de energia pela queima da biomassa (May et. al. 2013).

Uma alternativa comum para a redução da umidade de culturas é a aplicação de herbicidas, que são compostos sintéticos que atuam no controle do desenvolvimento vegetal. Os herbicidas agem em diferentes rotas metabólicas nas plantas, desencadeando uma série de alterações celulares e fisiológicas, podendo atuar como auxinas sintéticas; como bloqueadores do fluxo fotossintético de elétrons; ou bloqueando a biossíntese de aminoácidos, carotenoides e lipídeos (Kerbauy, 2008). Desse modo, o estresse oxidativo ocasionado pelos herbicidas afetando assim, a iniciação ou modificação do desenvolvimento de tecidos ou órgãos vegetais (Barbosa et. al. 2010).

Dentre os diferentes tipos de herbicidas disponíveis no mercado, enfatiza-se os herbicidas dessecantes. A dessecação, pelo do uso de produtos químicos, favorece a secagem rápida de plantas, uma vez que sua aplicação acelera o processo de perda de água (Lamego, et. al. 2013). O glyphosate é o herbicida com função dessecante mais vendido no mundo, sendo comercializado em diferentes sais e formulações; tem baixa toxicidade e não representa riscos de lixiviação para águas subterrâneas (FAO, 2014; Benbrook, 2016).

Esse herbicida atua na rota do ácido chiquímico, inibindo a ação da enzima 5enolpiruvil-chiquimato-3-fosfato-sintase

(EPSPs) que catalisa a condensação do erythrose 4-phosphate (E4P) e do fosfato piruvato (PEP), evitando a síntese do corismato (Herrmann e Weaver, 1999). O glyphosate é um herbicida não seletivo, sistêmico e pósemergente; absorvido pelas plantas a partir de suas folhas e seus caulículos novos, sendo, logo após, transportado por todas as partes da planta, atingindo vários sistemas enzimáticos $\mathrm{e}$ bloqueando o metabolismo de aminoácidos (Toledo et. al. 2012). Tem-se observado também o uso dessa molécula como maturador na cultura da cana de açúcar, uma vez que, inibindo a síntese de aminoácidos é possível aumentar o nível de sacarose na cultura da cana de açúcar (Solomon e Li, 2004).

A utilização do herbicida glyphosate poderia contribuir para a perda da umidade do sorgo biomassa, aumentando assim sua eficiência na geração de bioenergia. Contudo, não há pesquisas que elucidem a perda de umidade da biomassa colhida dessa cultura com a aplicação de dessecantes na parte aérea, antes da colheita. Assim, o objetivo dessa pesquisa foi avaliar a aplicação de doses de glyphosate na dessecação do sorgo biomassa. 


\section{Material e Métodos}

O experimento foi instalado e conduzido na casa-de-vegetação. $\mathrm{O}$ delineamento experimental utilizado foi blocos inteiramente casualizados, em esquema fatorial triplo $2 \times 5 \times 4$ (Cultivares, Doses de glyphosate, Épocas de coleta), constituídos por: duas cultivares de sorgo (BRS 716 e CR 1342); cinco doses de glyphosate $(0,720,1.440,2.160$ e $2.880 \mathrm{~g}$ i.a. $\left.\mathrm{ha}^{-1}\right)$ e quatro épocas de coleta das plantas $(7,14$, 21 e 28 dias após a aplicação), com 4 repetições. Cada repetição foi composta por uma planta conduzida em um vaso contendo $3,5 \mathrm{~L}$ de terra peneirada, calcareada e fertilizada. A cultivar CR 1342 é pertencente à empresa Ceres e a BRS 716 à Embrapa.

Por ocasião do plantio foi realizada a fertilização e correção do solo considerando a correção da saturação de bases para $60 \%$ com calcário dolomítico e o formulado 8-28-16, na dose de 4,2 g/vaso. No dia 18 de novembro de 2015 foi realizada a semeadura do sorgo, com 3 sementes por vaso, deixando apenas uma planta por vaso após raleio, realizado 12 dias após a semeadura. Quando as plantas estavam com 3 folhas definitivas foi realizada uma aplicação sob o solo dos vasos do formulado 20-00-20, na dose $2,5 \mathrm{~g} /$ vaso.

Durante a condução do ensaio foi realizada a irrigação com um sistema automatizado, com frequência de irrigação quatro vezes ao dia, conforme a demanda hídrica das plantas monitoradas por tensiômetros. O tratamento fitossanitário das plantas de sorgo ocorreu conforme as recomendações técnicas para a cultura. A temperatura no momento da aplicação das doses sob a parte aérea das plantas foi em torno de $28^{\circ} \mathrm{C}$, com umidade relativa de $38 \%$.

A aplicação das doses de glyphosate (Roundup, $720 \mathrm{~g} \mathrm{~kg}^{-1}$ i.a., WG, Monsanto), foi realizada aos 140 dias após o plantio no cultivar de sorgo CR 1342 e aos 167 dias após o plantio no cultivar BRS 716, por ocasião do início da fase de florescimento das cultivares. Para a aplicação das doses de glyphosate em cada tratamento, as plantas foram retiradas da casade-vegetação e distribuídas em linha ao lado de uma plataforma, especialmente desenvolvida para a aplicação do herbicida sob as plantas, utilizando equipamento costal de pressão constante $\left(\mathrm{CO}_{2}\right)$ equipado com bicos de jato plano, tipo leque, espaçados de $50 \mathrm{~cm}$, utilizando pressão de trabalho de $250 \mathrm{kPa}$. As doses foram calculadas considerando a aplicação de volume de calda de $200 \mathrm{~L} \mathrm{ha}^{-1}$, sendo preparadas em garrafas (tipo "pet") de dois litros.

As avaliações foram realizadas, em cada época de coleta das plantas, aos 7, 14, 21 e 28 dias após a aplicação das doses de glyphosate e encaminhadas ao laboratório para as determinações das seguintes características: biomassa fresca e seca do colmo e das folhas ( $\mathrm{g}$ planta $^{-1}$ ) e porcentagem de biomassa seca dos colmos e folhas. Para a determinação da biomassa fresca do colmo e folhas, as plantas foram colhidas, com o auxílio de uma ferramenta de corte, através de corte realizado na base das plantas, sendo as partes das plantas separadas manualmente. Para a determinação das biomassas secas dos colmos e folhas ( $g$ planta $\left.^{-1}\right)$ e da porcentagem de biomassa seca dos colmos e folhas, as partes das plantas de sorgo foram secas em estufa de circulação forçada de ar quente, mantidas à $60^{\circ} \mathrm{C}$, até peso constante da biomassa aferida. Após secagem o material foi pesado para determinação da biomassa seca dos colmos e folhas.

As variáveis foram submetidas à análise de variância pelo teste $\mathrm{F}(\mathrm{p}<0,05)$ e suas médias comparadas pelo teste de Tukey a 5\% probabilidade, sendo utilizado o programa Assistat 7.6 Beta (Silva e Azevedo, 2009).

\section{Resultados e Discussão}

Na Tabela 1, apresenta-se a análise de variância para todas as características da parte aérea avaliadas: biomassa fresca dos colmos e folhas, biomassa seca dos colmos e folhas e porcentagem de biomassa seca dos colmos e folhas de duas cultivares de sorgo biomassa 
submetidas à aplicação de doses de glyphosate, com avaliações em diferentes épocas de coleta após a aplicação do produto. Houve diferença significativa na maioria das características avaliadas para os fatores isoladamente.

Houve interação dupla entre as cultivares e doses de glyphosate aplicadas para todas as características, exceto para biomassa seca das folhas e porcentagem de biomassa seca dos colmos. Houve interação dupla entre as cultivares e épocas de coleta de plantas para biomassa fresca das folhas e porcentagem de biomassa seca dos colmos. Assim como, houve interação dupla entre doses e épocas de coleta para todas as características estudadas, exceto para biomassa fresca e seca dos colmos. Por fim, houve interação tripla apenas para a porcentagem de biomassa seca do colmo.

Tabela 1. Análise de variância para a biomassa fresca dos colmos (BFC) e folhas (BFF), biomassa seca dos colmos (BSC) e folhas (BSF), porcentagem de biomassa seca dos colmos (BSC\%) e folhas (BSF\%) avaliadas em plantas de duas cultivares de sorgo submetidas à aplicação de glyphosate, em diferentes épocas de colheita. Jaguariúna (SP), 2016.

\begin{tabular}{|c|c|c|c|c|c|c|c|}
\hline \multirow{2}{*}{$\mathrm{FV}$} & \multirow{2}{*}{ GL } & \multicolumn{6}{|c|}{ Quadrados médios } \\
\hline & & $\mathrm{BFC}$ & $\mathrm{BFF}$ & $\mathrm{BSC}$ & BSF & $\mathrm{BSC} \%$ & $\mathrm{BSF} \%$ \\
\hline Cultivar (C) & 1 & $857185,18^{* *}$ & $68895,81^{* *}$ & $9798,62^{* *}$ & $5765,75^{* *}$ & $729,75^{* *}$ & $4601,26^{* *}$ \\
\hline Doses (D) & 4 & $489285,58^{* *}$ & $33213,28^{* *}$ & $57549,17^{* *}$ & $2574,12^{* *}$ & $62,82^{* *}$ & $1670,41^{* *}$ \\
\hline Época (E) & 3 & $68040,41^{* *}$ & $24542,00^{* *}$ & $2114,30^{* *}$ & $2517,42^{* *}$ & $116,62^{* *}$ & $5156,83^{* *}$ \\
\hline Int. C x D & 4 & $23424,51^{*}$ & $2476,39^{* *}$ & $1191,01^{*}$ & $66,74^{\mathrm{ns}}$ & $7,52^{\mathrm{ns}}$ & $10,8437^{*}$ \\
\hline Int. $\mathrm{C}$ x E & 4 & $7511,69^{\mathrm{ns}}$ & $2082,93^{* *}$ & $713,63^{\mathrm{ns}}$ & $60,49^{\text {ns }}$ & $12,08^{*}$ & $73,9831^{\mathrm{ns}}$ \\
\hline Int. D x E & 12 & $10044,59^{\mathrm{ns}}$ & $1140,39^{* *}$ & $362,02^{\mathrm{ns}}$ & $126,93^{* *}$ & $7,68^{*}$ & $276,98^{* *}$ \\
\hline Int.C x D x E & 12 & $8204,99^{\text {ns }}$ & $477,22^{\mathrm{ns}}$ & $499,75^{\mathrm{ns}}$ & $54,61^{\mathrm{ns}}$ & $10,12^{*}$ & $135,76^{\mathrm{ns}}$ \\
\hline Tratamentos & 39 & $85991,71^{\text {** }}$ & $7972,84^{* *}$ & $6758,57^{* *}$ & $672,85^{* *}$ & $41,30^{* *}$ & $819,78^{* *}$ \\
\hline Resíduo-E & 120 & 8265,03 & 367,22 & 439,55 & 42,97 & 3,34 & 104,43 \\
\hline Total & 159 & & & & & & \\
\hline
\end{tabular}

Observou-se que a molécula de glyphosate foi ineficiente na dessecação do colmo visto que a interação dose e época de coleta para a biomassa fresca do colmo não foi significativa. Isso pode ter sido ocasionado pela provável baixa translocação da molécula na planta, diminuindo assim sua toxicidade no sorgo biomassa. McWhorter et al. (1980) estudando o efeito do glyphosate em Sorghum halepense identificaram uma forte correlação entre umidade relativa do ar e a translocação de glyphosate na planta. Os autores verificaram que entre 45 e $100 \%$ de umidade relativa a translocação foi duas vezes maior. Nesta pesquisa realizada com cultivares de sorgo biomassa, a umidade relativa no dia da aplicação estava em 38\%. Outro fator que pode ter contribuído para esse resultado é o fato do sorgo biomassa ser uma cultura tolerante a seca, de forma que, fatores relacionados ao ajuste osmótico e mudanças na elasticidade dos tecidos vegetais podem evitar a perda de água (Jones e Turner, 1978).

A redução observada na biomassa fresca do colmo e das folhas ao longo do tempo, verificado pelas diferentes épocas de coleta de plantas, foi acelerada com a aplicação do produto, como pode ser observado nas Figuras 1 e 2, provavelmente decorrente da aceleração da senescência das folhas por estresse oxidativo. Esses resultados eram esperados, pois o glyphosate inibe a síntese de aminoácidos (triptofano, tirosina e fenilalanina) e, à medida que os sintomas se agravam, observa-se o amarelecimento progressivo das folhas, seguido de necrose dos tecidos (Rodrigues e Almeida, 2005). Ressalta-se também que a aplicação do glyphosate ocorreu logo após o florescimento, quando a taxa de fotossíntese das folhas é drasticamente reduzida com a senescência 
natural das folhas de sorgo biomassa por isso observou-se a queda de biomassa fresca na testemunha nas diferentes datas de coleta.

Dessa forma, na Figura 1 apresentam-se os valores relativos ao desdobramento da interação significativa entre as duas cultivares de sorgo biomassa em função das doses de glyphosate para a característica de biomassa fresca dos colmos. A biomassa fresca dos colmos apresentou tendência de queda com a aplicação de glyphosate até a dose de $1.847,5$ e 2.132 g i.a. $\mathrm{ha}^{-1}$, respectivamente para as cultivares BRS 716 e CR 1342, com elevação da biomassa fresca do colmo por planta após essas doses, detonando uma perda de eficiência do glyphosate para dessecação do sorgo biomassa em doses mais elevadas.

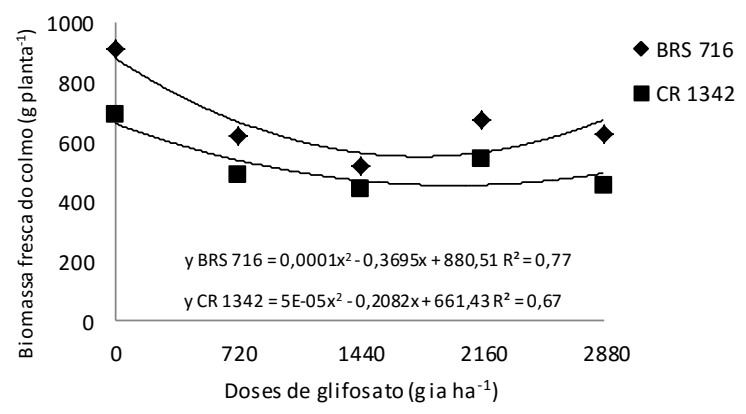

Figura 1. Desdobramento da interação significativa entre as duas cultivares de sorgo biomassa em função das doses de glyphosate para a característica de biomassa fresca dos colmos. Jaguariúna (SP), 2016.

São apresentados na Figura 2 os valores relativos ao desdobramento da interação significativa entre as duas cultivares de sorgo biomassa em função das doses de glyphosate para a característica de biomassa fresca das folhas. Verificou-se nas cultivares BRS 716 e CR1342 que à medida que as doses de glyphosate aumentam a produção de biomassa fresca das folhas diminuiu, até aproximadamente a dose 2.160 g i.a. ha ${ }^{-1}$.

$\mathrm{Na}$ Figura 3, apresenta-se o desdobramento da interação significativa entre as duas cultivares de sorgo biomassa em função das diferentes épocas de coletas realizadas aos 7, 14, 21 e 28 dias após a aplicação do glyphosate, para a característica de biomassa fresca das folhas. $\mathrm{O}$ comportamento foi semelhante às características analisadas anteriormente, quando houve uma redução dos valores da biomassa fresca das folhas das plantas do sorgo à medida que foram avançando as épocas de colheitas.

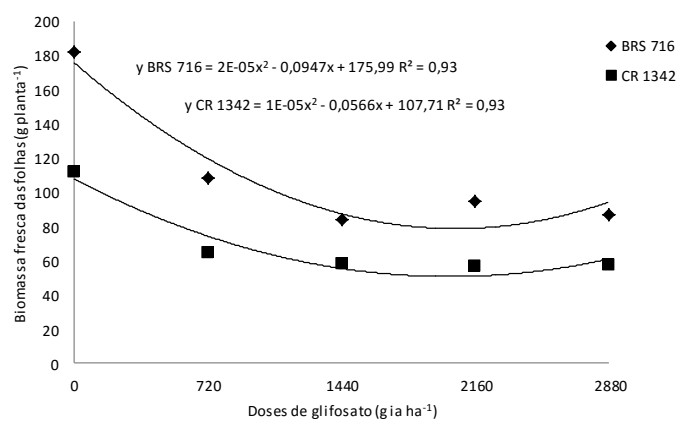

Figura 2. Desdobramento da interação significativa entre as duas cultivares de sorgo biomassa em função das doses de glyphosate para a característica de biomassa fresca das folhas. Jaguariúna (SP), 2016.

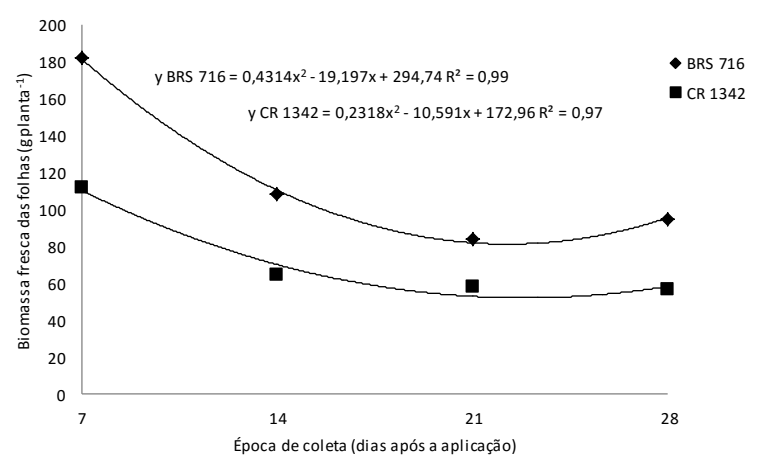

Figura 3. Desdobramento da interação significativa entre as duas cultivares de sorgo biomassa em função das diferentes épocas de coletas realizadas aos 7, 14, 21 e 28 dias após a aplicação do glyphosate, para a característica de biomassa fresca das folhas. Jaguariúna (SP), 2016.

$\mathrm{Na}$ Figura 4, apresenta-se o desdobramento da interação significativa entre as 
doses de glyphosate em função das diferentes épocas de coletas realizadas, para a característica de biomassa fresca das folhas. Verificou-se que, há uma relação entre as doses aplicadas na cultura do sorgo biomassa e as diferentes épocas de coletas.

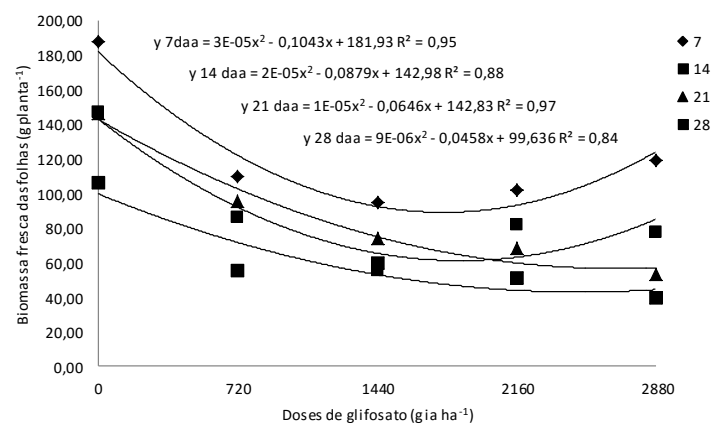

Figura 4. Desdobramento da interação significativa entre as doses de glyphosate em função das diferentes épocas de coletas realizadas aos 7, 14, 21 e 28 dias após a aplicação, para a característica de biomassa fresca das folhas. Jaguariúna (SP), 2016.

Observa-se que ocorreu uma redução da biomassa fresca de folhas a partir da aplicação das dosagens aplicadas de 1.440 a 2.880 g i.a. $\mathrm{ha}^{-1}$ de glyphosate, e com o avanço das colheitas realizadas observou-se uma diminuição dos valores de biomassa fresca das folhas (Figura 4). Monquero et al. (2010) verificaram, em forrageiras perenes, que essas gramíneas demoram mais a serem dessecadas pelo glyphosate, de forma que, após 14 dias da aplicação do herbicida, em média, somente $65 \%$ das plantas estavam secas.

São apresentados na Figura 5 os valores relativos ao desdobramento da interação significativa entre as duas cultivares de sorgo biomassa em função das doses de glyphosate para a característica de biomassa seca dos colmos. Os cultivares BRS 716 e CR1342 apresentaram uma redução na produção de biomassa seca dos colmos à medida que foram aplicadas as maiores doses de glyphosate, provavelmente, em função do consumo de fotoassimilados pelas células da planta após a aplicação do produto testado. De mesma forma, Carvalho et al. (2008), estudando Sorghum halepense, verificaram perda de biomassa seca da planta após a aplicação do glyphosate.

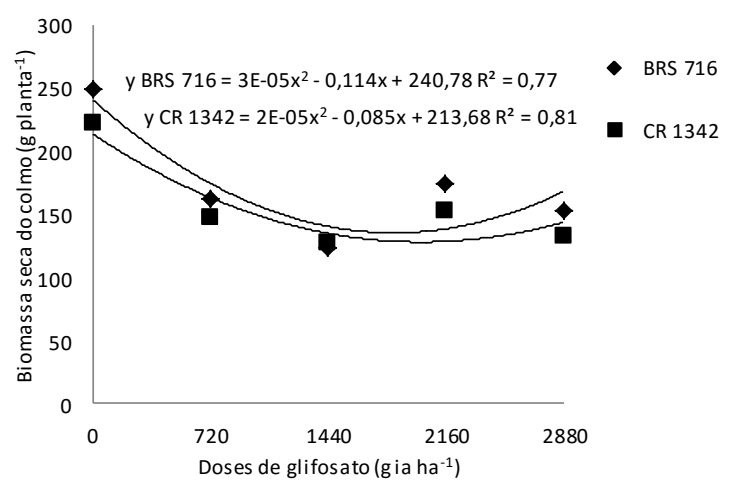

Figura 5. Desdobramento da interação significativa entre as duas cultivares de sorgo biomassa em função das doses de glyphosate para a característica de biomassa seca dos colmos. Jaguariúna (SP), 2016.

$\mathrm{Na}$ Figura 6, apresenta-se o desdobramento da interação significativa entre as doses de glyphosate em função das diferentes épocas de coletas realizadas, para a característica de biomassa seca das folhas. Observa-se que há uma relação entre as doses aplicadas na cultura do sorgo biomassa e diferentes épocas de coletas. Diante disto, verificou-se, que à medida que se realizada a colheita da produção de biomassa seca das folhas nas diferentes épocas de coleta, ocorreu uma redução na produção da biomassa, devido à aplicação das dosagens aplicadas de $1.440 \mathrm{a}$ $2.880 \mathrm{~g}$ i.a. ha ${ }^{-1}$ de glyphosate.

Observa-se na Figura 7 o desdobramento das interações significativas entre duas cultivares de sorgo biomassa, doses de glyphosate e diferentes épocas de coletas, para a característica porcentagem da biomassa seca dos colmos onde, ocorreu uma redução na porcentagem produção da biomassa seca dos colmos, devido à aplicação das dosagens de 1.440 a 2.880 g i.a. $\mathrm{ha}^{-1}$ de glyphosate nas diferentes épocas de coleta a partir dos 14 dias após aplicação para 
cultivar BRS 716. Já na cultivar CR 1342 estes resultados foram observados aos 28 dias após a aplicação do glyphosate.

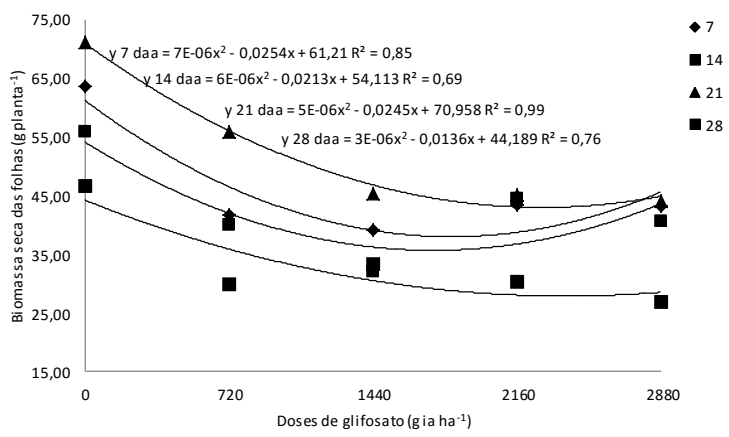

Figura 6. Desdobramento da interação significativa entre as doses de glyphosate em função das diferentes épocas de coletas realizadas aos 7, 14, 21 e 28 dias após a aplicação para a característica de biomassa seca das folhas. Jaguariúna (SP), 2016.

A porcentagem de biomassa seca do colmo, principal característica estudada para avaliar a umidade da massa produzida de sorgo biomassa, apresentou tendência de queda após a aplicação do glyphosate, comparativamente à testemunha sem a aplicação do produto, mas com comportamento variável para cada cultivar estudada em cada época de coleta de plantas (Figura 7), demonstrando um efeito inverso do esperado para um dessecante. Mas, com tendência de elevação da porcentagem de biomassa seca do colmo das plantas (redução da umidade) apenas após a dose de $2.160 \mathrm{~g}$ i.a. ha ${ }^{1}$, mas não atingindo valores da porcentagem da massa seca do colmo superiores à testemunha, sem a aplicação do produto, até a dose limite estudada de $2.880 \mathrm{~g}$ i.a. ha ${ }^{-1}$.

Assim, é possível observar na Figura 7 que os maiores valores da porcentagem biomassa seca do colmo foram obtidos nas plantas sem a aplicação de glyphosate, resultando em menores valores de umidade do colmo, demonstrando que, para o objetivo dessa pesquisa, referente ao uso de dessecante para o aumento da biomassa seca da planta colhida de sorgo biomassa e, consequente redução da sua umidade, o produto pesquisado não foi eficiente.

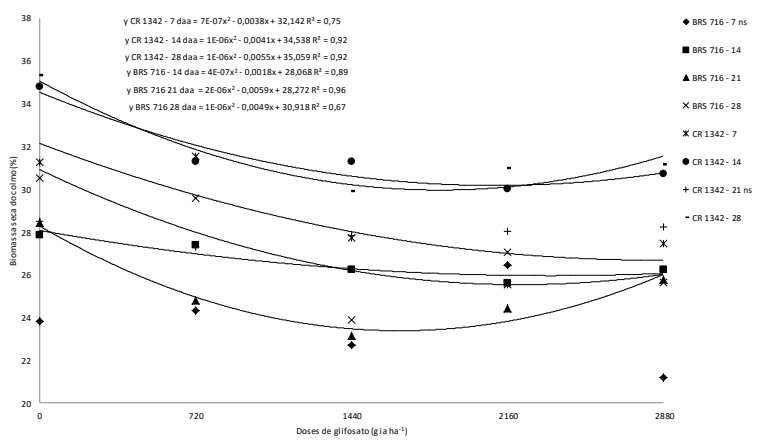

Figura 7. Desdobramento da interação significativa entre as duas cultivares de sorgo biomassa, doses de glyphosate e diferentes épocas de coletas para a característica porcentagem da biomassa seca dos colmos. Jaguariúna (SP), 2016.

Monquero et al. (2010) relataram que algumas plantas de cobertura são menos sensíveis ao glyphosate, demorando mais tempo para serem totalmente dessecadas após a aplicação do herbicida. Dessa forma, possivelmente, poderia ocorrer uma diminuição da umidade dos colmos do sorgo biomassa após a data limite de coleta de plantas de 28 dias aferida por essa pesquisa. Contudo, é importante frisar que o produtor agrícola dificilmente poderia aguardar prazos mais longos para que os colmos das plantas apresentassem elevada redução de umidade, já que há a necessidade de entrada de novas operações agrícolas para o cultivo da safra subsequente ao sorgo biomassa cultivado.

Na Figura 8, observa-se o desdobramento da interação significativa entre as duas cultivares de sorgo biomassa em função das doses de glyphosate para a característica de porcentagem da biomassa seca das folhas. Verificou-se que os cultivares BRS 716 e CR1342 apresentaram comportamentos semelhantes, e à medida que as doses de glyphosate aumentavam a porcentagem da biomassa seca das folhas apresentavam incrementos em seus valores médios. 


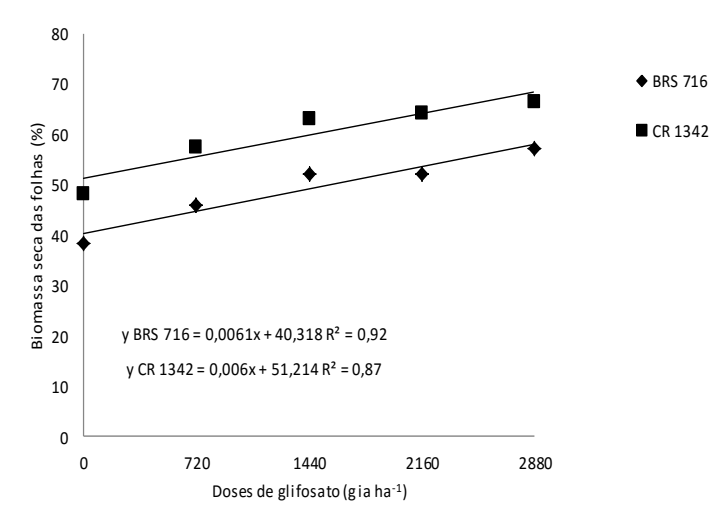

Figura 8. Desdobramento da interação significativa entre as duas cultivares de sorgo biomassa em função das doses de glyphosate para a característica porcentagem da biomassa seca das folhas. Jaguariúna (SP), 2016.

Segundo Brasi et al. (2008) que verificaram em plantas de nabo, com intensa ramificação e altura variando entre 1 e $1,8 \mathrm{~m}$, com sistema radicular pivotante e agressivo, que há a necessidade de maior tempo para que o herbicida transloque por toda a planta, em função do seu vigor, demonstrando seus efeitos de forma mais tardia.

$\mathrm{Na}$ Figura 9, são apresentados os desdobramentos da interação significativa entre as doses de glyphosate em função das diferentes épocas de coletas realizadas aos 7,14, 21 e 28 dias após a aplicação, para a característica de porcentagem da biomassa seca das folhas. Observou-se que, à medida que as doses de glyphosate aumentaram, houve um aumento na porcentagem de biomassa seca das folhas ao longo das épocas avaliadas, apresentando seu ponto ótimo aos 21 dias após a aplicação da dose de 2.880 g i.a. ha ${ }^{-1}$ de glyphosate, demonstrando que as folhas do sorgo biomassa secam rapidamente com a aplicação do glyphosate, embora não tenha sido observado efeito similar para o colmo, como anteriormente discutido.

Estes dados corroboram com Timossi et al. (2006) que, avaliando a porcentagem de controle de $B$. decumbens e $B$. brizantha, observaram uma taxa de controle de 99,5 e $98,5 \%$, respectivamente, aos 28 dias após a aplicação da dose 2.880 g i.a. ha ${ }^{-1}$ de glyphosate.

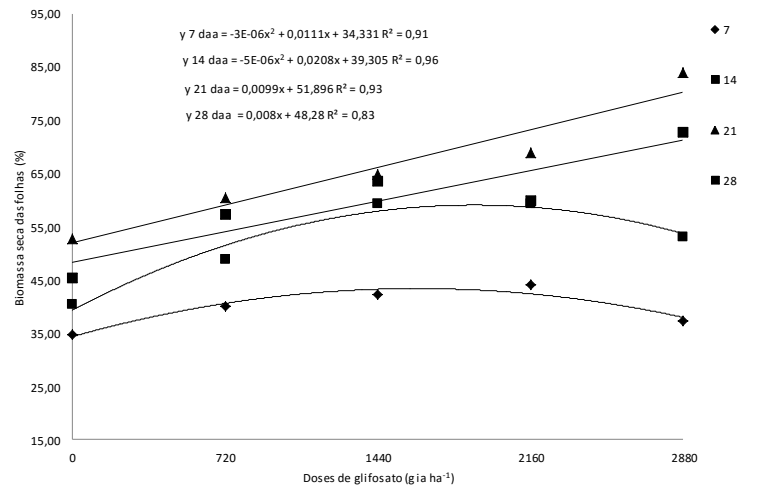

Figura 9. Desdobramento da interação significativa entre as doses de glyphosate em função das diferentes épocas de coletas realizadas aos 7, 14, 21 e 28 dias após a aplicação, para a característica de porcentagem da biomassa seca das folhas. Jaguariúna (SP), 2016.

\section{Conclusões}

A aplicação das doses do glyphosate reduziu a umidade nas folhas do sorgo biomassa, mas não foi eficaz no processo de redução de umidade dos colmos das cultivares BRS 716 e CR1342 até 28 dias após a aplicação do produto.

\section{Referências}

Barbosa, K.B.F.; Costa, N.M.B.; Alfenas, R.C.G.; De Paula, S.O.; Minim, V.P.R.; Bressan, J. Estresse oxidativo: conceito, implicações e fatores modulatórios. Revista de Nutrição, v.23, n.4, p.629-643, 2010.

Benbrook, C.M. Trends in glyphosate herbicide use in the United States and globally. Environmental Sciences Europe, v.28, n.3, p.02-15, 2016.

Brasi, L.A.C.S.; Denucci, S.; Portas, A.A. Nabo - adubo verde, forragem e bioenergia. Disponível em: <www.infobibos.com/acesso>> Acesso em: 02 out. 2016.

Carvalho, S.J.P.; Dias, A.C.R.; Damim, V.; Nicolai, M.; Christoffoleti, P.J. Glifosato aplicado com diferentes concentrações de uréia ou sulfato de amônio para dessecação de plantas daninhas. Pesquisa Agropecuária Brasileira, 
v.43, n.11, p.1501-1508, 2008.

FAO. Food and Agriculture Organization. Glyphosate. Disponível em: $\langle w w w . f a o . o r g / a c e s s o>>$. Acesso em: 30 set. 2016.

Herrmann, K.M.; Weaver, L.M. The shikimate pathway. Annual Review of Plant Physiology and Plant Molecular Biology, v.50, n.1, p.473503, 1999.

Jones, M.M.; Turner N.C. Osmotic adjustment in leaves of sorghum in response to water deficits. Plant Physiology, v.61, n.1, p.122-126, 1978.

Kerbauy, G.B. Fisiologia Vegetal. Rio de Janeiro: Guanabara, 2008. v.1, cap.9, p.226233.

Lamego, F.P.; Gallon, M.; Basso, C.J.; Kulczynski, S.M.; Ruchel, Q.; Kaspary, T.E. et al. Dessecação pré-colheita e efeitos sobre a produtividade e qualidade fisiológica de sementes de soja. Planta Daninha, v.31, n.4, p.929-938, 2013.

Lave, L.B.; Burke, C.I.; Tyner, W.E.; Dale, V.H.; Halvorsen, K.E.; Hill, J.P.D. et al. Renewable fuel standard: Potential economic and environmental effects of U.S biofuel policy. Washington: The National Academies Press, 2011. v.1, cap.3, p.79-100.

May, A.; Albuquerque Filho, M.R.; Rodrigues, J.A.S.; Landau, E.C.; Parrella, R.A.C.; Massafera, R. Cultivares de sorgo para o mercado brasileiro na safra 2011/2012. Documentos, v.117, n.1, p.05-28, 2011.

May, A.; Silva, D.D.; Santos, F.C. Cultivo do sorgo biomassa para a cogeração de energia elétrica. Documentos, v.152, n.1, p.09-66, 2013.

McWhorter, C.; Jordan, T.; Wills, G. Translocation of ${ }^{14} \mathrm{c}$-glyphosate in soybeans (Glycine max) and johnsongrass (Sorghum halepense). Weed Science, v.28, n.1, p.113118, 1980.
Monquero, P.; Milan, B.; Silva P.V.; Hirata, A.C.S. Intervalo de dessecação de espécies de cobertura do solo antecedendo a semeadura da soja. Planta Daninha, v.28, n.3, p.561-573, 2010

Rodrigues, B.N.; Almeida, F.S. de. Guia de herbicidas. Londrina: [s.n], 2005. v.1, cap.5, p.324-355.

Silva F.A.S.; Azevedo C.A.V. The assistat software version 7.7 and its use in the analysis of experimental data. African Journal of Agricultural Research. v.11, n.39, p.37333740, 2016.

Solomon, S.; Li, Y.R. Chemical ripening of sugarcane: Global progress and recent developments in china. Sugar Tech, v.6, n.4, p.241-249, 2004.

Steduto, P.; Hsiao, T.C.; Fereres E.; Raes D. Crop yield response to water. Roma: FAO, 2012, v.66, cap.3, p.144-154.

Timossi, P.C.; Durigan, J.C.; Leite, G.J. Eficácia de glyphosate em plantas de cobertura. Planta Daninha, v.24, n.3, p.475-480, 2006.

Toledo, M.Z.; Cavariani, C.; França-Neto, J.B. Qualidade fisiológica de sementes de soja colhidas em duas épocas após dessecação com glyphosate. Revista Brasileira de Sementes, v.34, n.1, p.134-142, 2012. 